\title{
Holistic model to analyze and prioritize urban sustainable buildings for public services
}

\author{
Francesc PARDO-BOSCH ${ }^{a}$, PhD; Antonio AGUADO ${ }^{b}, \mathrm{PhD}$; and Marçal PINO ${ }^{c}$
}

\begin{abstract}
a PhD MSc BSc Civil Engineer. Dept. of Civil and Environmental Engineering, Polytechnic Univ. of Catalonia, Jordi Girona 1-3, 08034 Barcelona, Spain - Institute for Public Governance and Management, ESADE Business School, University Ramon Llull, Spain. e-mail: francesc.pardo@esade.edu (corresponding author)

${ }^{b}$ PhD MSc BSc Civil Engineer, Full Professor, Dept. of Civil and Environmental Engineering, Polytechnic Univ. of Catalonia, UPC, Jordi Girona 1-3, 08034 Barcelona, Spain. e-mail: anotnio.aguado@upc.edu

${ }^{c}$ MSc BSc Civil Engineer. Dept. of Civil and Environmental Engineering, Polytechnic Univ. of Catalonia, UPC, Jordi Girona 1-3, 08034 Barcelona, Spain. e-mail: mpinofont@gmail.com
\end{abstract}

\begin{abstract}
A Multi-Criteria Decision-Making (MCDM) methodology is presented in this paper that is used to analyse and to assess public-service building projects for the promotion of smart sustainable cities. Its main purpose is to compare different types of projects (hospitals, schools, museums, etc.) and to prioritize the investments that present the most favourable global results. The methodology, known as MIVES, constructs a model that assists decision-making on the basis of consistent and transparent criteria. It incorporates the value function concept that attaches a value to different types of variables for the purpose of arriving at a final value in relation to predefined criteria. In this study, the model is based on the three basic pillars of sustainability (economy, environment, and society) presented in a triple-layer decision tree. Its application to four urban projects, presented as examples, showed encouraging results with a wide range of values.
\end{abstract}

\section{1.- Introduction}

Nowadays, over half of the global population live in urban areas. It is estimated that this percentage will grow by $15 \%$ over the following 30 years (2050), when approximately 2.5 million people would therefore be living in urban areas areas (Ahvenniemi et al., 2017 and United Nation, 2018). This rapid growth of urban areas is a problem that has to be solved through a paradigmatic shift in the governance model of cities that need sustainable and flexible management tools and long-term planning (Mendizabal et al. 
2018). Now is the time to search for innovative solutions to prevent urban population growth from becoming a critical issue (Carli et al, 2017).

Cities that wish to respond to the above-mentioned challenge and the new model of urbanization will have to promote the smart city concept (Suganthi, 2018). Public managers had assumed that this new concept of a city would mean the design and planning of services offered in more sustainable ways through the use of new technologies and innovative solutions. Unfortunately, the idea of smart cities has been dismissed as nothing other than a buzz word, that has now outlived its usefulness, because of its focus on the installation of sensors and the development of apps tracking smart city targets without paying heed to the objectives of sustainable development (Kunzmann, 2014; Marsal-Llacuna, ColomerLlinàs, \& Meléndez-Frigola, 2015; Shelton et al., 2015 and Bibri \& Krogstie 2017). The development of the smart city should instead make an explicit contribution to the goal of urban sustainability in terms of social inclusion, economic viability and ecologic preservation (Lopez-Carreiro \& Monzon, 2018), especially, if it is taken under consideration that authors like Gray et al. (2009) or Alcaraz-Quiles et al. (2014) ensure that sustainability approaches are an excellent way to promote transparency in decision-making and to improve profitability of public investments.

Cities offer a range of services to the general public including health services, educational facilities, policing, culture, water and energy supplies, and transport, among others. Population growth means that the infrastructures needed to accommodate these services will increase (Phillis, Kouikoglou, \& Verdugo, 2017), because we are also facing an increasingly demanding society. Buildings and transportation systems represent the majority of public infrastructures. Buildings are the basis of human activity and ensure the wellbeing of the population (Pearce, 2017). However, their social contribution comes with economic and environmental costs (Ahmad \& Thaheem, 2018). According to Cabezas et al. (2014), . Buildings are one of the most relevant elements in cities and play a very significant role in consumption of energy and natural resources all over the world. In fact, the building sector in Europe consumes $40 \%$ of all energy and around 60\% of all electricity that is generated (Gynther et al., 2015) and EU highlights the importance of reducing the environmental burden of buildings throughout all the stages of its lifetime (Kylili \& Fokaides, 2017). One third of this consumption is generated by non-domestic buildings (OzawaMeida et al., 2017). According to Chidiac et al., (2011), Ascione et al. (2015) and Xu et al. (2015), public buildings are by far the best target with the highest potential for energy and water savings. 
Most public buildings (e.g., offices, schools and hospitals, as well as galleries and museums) were designed and built at a time when insufficient consideration was given to energy and water efficiency and the associated life cycle costs (Bertone et al. 2016). The same is true in some cases, for other public infrastructure, the construction of which responds to no clear need or utility (Pardo-Bosch and Aguado, 2016), squandering natural resources (raw materials), scarce urban spaces, and public money. It should be remembered that Western democracies are experiencing economic and financial difficulty, and with no margins for tax increases, the only way to promote their own growth is through the effective use of limited economic resources (Nestico, Morano \& Sica, 2018).

Although this gap has been detected in the literature, to the best of the authors' knowledge, in the field of public buildings, there are no empirical tools to assess their sustainability and to incorporate environmental, social and economic aspects in a real and practical way (Banani et al. 2016). The lack of any such model has basically led designers and building managers to make intuitive decisions, albeit based on their own technical knowledge (Pan et al, 2012). One way to solve this dilemma is, according to Mendizabal et al. (2018), to develop decision-making tools with the aim of improving public governance of cities, and thereby guarantee their sustainability and resilience.

Aware of that need, the objective of this paper is to present a model for sustainability assessments of any kind of urban public building at the design stage, through the quantification of the Sustainable Building index $\left(B_{s}\right)$, based on MIVES, a Multi-Criteria Decision-Making (MCDM) model. MIVES serves to analyse buildings with varied characteristics (different locations and costs), designed to offer different public services (schools, libraries, hospitals, sport centres, etc.), in order to prioritize the most sustainable ones, thereby assisting public service managers, as suggested in (Pearce, 2017), with the planning needs for future facilities. When a smart city is planned with this type of collaborative approach, not only is less desirable infrastructure avoided, but new streams of project financing may also open up (Callaway, 2016). The policy that public managers follow for investing in public buildings and other civil infrastructures will clearly affect future users and society as a whole.

This paper is divided in 6 sections. Having outlined the aims of the research and its significance in this Introduction, in section 2, Theoretical background, a review of the literature on sustainability and multicriteria decision-making models will be presented. Then, in Section 3, the decision model and each of its components will be defined. In Section 4, four real projects will be analysed to show the utility of the 
model. Traceability of the results is ensured for any eventual use by different entities and for reproduction of the results among researchers. The Discussion, in Section 5, will present a sensitivity analysis and will compare $\mathrm{B}_{\mathrm{s}}$ with a further two methodologies. Finally, the Conclusions will be presented in section 6 . Regarding the research methodologies followed in this paper, the different technical elements that form part of $B_{s}$ were compiled from literature review and from interviews in workshops with decision makers and stakeholders and a combination of both, as recommended by Pan et al. (2012). A panel of 10 experts was formed, consisting of public managers, academics, engineers/architects and consultants, whose task was to apply their experience to the weighting of the decision models for the assessment of the projects in the case study.

\section{2.- Theoretical background}

\section{1.- Sustainability}

According to Ribeiro et al. (2018), sustainable practices would reduce the problems arising from disorderly urban planning that affects the vast majority of city dwellers across the world. In that sense, the sustainable development of cities can always be seen as both an opportunity and a challenge (Wu, 2014; Addanki \& Venkataraman, 2017; Sheally et al., 2018; and Yin et al. 2018); although such statements beg the question of what sustainability actually means. In its report entitled Our Common Future, the World Commission on Environment and Development (1987) defined sustainable development as the capacity to meet the needs of the present without compromising the ability of future generations to meet their own needs. There are inherent limits to the concept of sustainable development, which although not absolute, are imposed by the limitations of modern technology and the organization of environmental resources for social cohesion. A holistic approach that considers multidimensional aspects is therefore needed to respond to the objective of the 2030 agenda for sustainable development (Suganthi, 2018). Hence, sustainability studies should consider the inseparable nature of environmental, social, and economic aspects of development activities (Mori \& Christodoulou, 2012; United Nations, 2013; Veldhuizen et al., 2015, and Huang et al. 2016).

Environmental sustainability refers to one segment of sustainability in which the positive and negative impact of human action on the environment is assessed. It analyses aspects such as air and water quality, the conservation of natural resources, energy use, and waste management, among others, with the 
objective of maintaining and where necessary restoring the natural environment. Economic sustainability, in relation here to public authorities, refers to the management of economic and financial resources, with the objective of maintaining current public services, complying with financial obligations, maintaining debt at a reasonable level, and ensuring future income, while maintaining public confidence (Controller and Auditor-General Office, 2013), making only affordable and reasonable investments. The economic sustainability of local and regional government is of great concern (Drew \& Dollery, 2015). Social sustainability is responsible for understanding and responding to the needs of different populations, seeking to promote long-term collective welfare. In that sense, social sustainability should guarantee, inclusion, equity, accessibility to public services, employment, and security, and should include local community values as part of the decision-making process. Cities that offer such services to their inhabitants will be contributing to their overall holistic development.

In the building sector, as in other sectors, sustainability studies often over-emphasize the environmental aspects of the analysis, focusing attention on energy use, raw material, the indoor climate and other environmental issues (Nilashi et al., 2015; and Suganthi, 2018).

It is as well to recall that the concept of sustainability sprung from the concerns of environmentalists who initiated the very first studies of the environment, lending greater strength to environmental variables. The great problem of sustainable development is its tangible expense compared to its often-intangible benefits that are not always evident in the short term. Therefore, the solution, according to Persson \& Grönkvist (2015) and Ahmad \& Taheem (2018), is to develop frameworks for realistic evaluations of the advantages and disadvantages of sustainable development. It is imperative to assess sustainability in this context through tools to support decision-making for the selection of civil works that will inevitably have to be financed with public funds (Guarini et al., 2017; Nestico, Morano \& Sica, 2018).

\section{2.- Multi-Criteria Decision-Making tools}

When problems are complex and it is necessary to assess more than one criterion, as in the case of sustainability assessment, Multi-Criteria Decision-Making (MCDM) tools are very useful. MCMD, based on different mathematical tools, is capable of structuring and solving real-world problems by assessing multiple variables (Selih et al., 2008; and Nilashi et al., 2015). Moreover, according to Huang et al. (2011), they are also highly appropriate when auditing projects. Decision-makers often use these models when 
they have to choose between different alternatives based on their potential impacts (Dong et al. 2018). MCDM models help them to select the most promising solution from a holistic point of view considering a set of indicators that are defined by the desired outcomes. According to Keeney and Raiffa (1993), the set of indicators of each model should be complete, operational, decomposable, non-redundant, and minimal. Other authors added they should also be discriminant, comprehensive, and measurable.

The key feature of these models is their capacity to deconstruct the problem of decision-making into discrete steps, comparing the relative importance of the associated variables. In doing so, the subjectivity of the analysis, and, for instance, of the selection process, is minimal (Linkov \& Morberg, 2011). Organizing the variables with these models avoid overlap and repetition in the analysis, which is very common in sustainability analysis, due to the interrelated nature of environmental, social, and economic criteria (Si et al., 2016).

Prioritizing public investments for building public infrastructures is a decision based on multiple and conflicting variables. MCDM models structure the analysis, by incorporating expert assessments and by including the interests of all stakeholders (Kabir et al. 2013). However, according to the same authors, these tools are not frequently used in the building sector. They found only 33 studies from among 330 research papers, most of which on models focusing only on the study of the structure, as shown in Balali et al. (2010), Medineckiene et al. (2015), and Rodríguez-Álvarez (2016).

There are various mathematical tools for developing MCDM models. Perhaps the most well known are Elimination and Choice Expressing the Reality - ELECTRE (Benayoun, Roy \& Sussman, 1966), Analyttical Hierarchy Process (Saaty, 1980), TOPSIS (Hwang \& Yoon, 1981), PROMETHEE (Brans \& Vincke, 1985) or VIKOR (Opriovic, 1998). In this case, the authors decided to use MIVES, a methodology that is in theory applicable to any kind of decision-making process, which great advantage is that it combines Multi-Criteria Analysis (MCA) theory in a simple way with Multi-Attribute Utility Theory MAUT theory (San-Jose and Garrucho, 2010; Aguado et al., 2012; Melé et al. 2015; Pardo-Bosch \& Aguado, 2015; del Caño et al., 2016; de la Fuente et al., 2017). According to Pardo-Bosch and Aguado (2015), the configuration of the decision model is divided into 4 stages. 1) Identification of a problem and the precise definition of the decision that has to be taken. 2) Development of the decision tree, which is divided into three categories: requirements, criteria and indicators. (3) Defining the relative weight of each of the elements of the decision tree using Analytic Hierarchy Process (AHP) (4) The setting of a value function for each indicator that converts its 
value to a dimensionless scale from 0 to 1 . When the model has been developed, the decision-makers can assess as many projects as they wish. Decision-makers only have to evaluate each indicator (through the variables that define them) and multiply their values by their corresponding weights.

\section{3.- The Decision Model for assessing the sustainability of urban public-service buildings}

In this section, the Multi-Criteria Decision-Making (MCDM) model is presented that was developed to assess the sustainability of all types of urban public service buildings, by quantifying their attributes on the Sustainable Building index $\left(B_{s}\right)$. $B_{s}$ can be used to analyse any public building, such as schools, hospitals, sports centres, museums, etc. with the aim of prioritizing those that contribute to the sustainable development of the city and the region. This section is sub-divided into the four main stages into which the MIVES model is defined (see section 2.2): Definition of decisions, the requirements tree, indicator weights, and value functions.

\section{1.- Definition of decisions}

The following concepts have to be defined, in order identify the problem that we need to solve and to establish the decisions that we wish to take: scope of the decision, life cycle, and the perspective of the decision-maker.

Scope of the decision: defines which elements (projects) can be considered in the decision process. Its definition is essential, in order to define the dimensions of the study. In this paper, any public buildings are included in the scope, regardless of their utility, location, dimension, and cost.

Life cycle incorporates the temporal dimension in the study, as the phases of the structure that have to be considered by the analysis. In the field of public works, and of course in building construction, the life cycle of a structure can be divided in four different stages: design, construction, operational, and demolition. In this case, the project phase is considered, although the analysis will also use data related to the construction and operation phases. In this sense, a very important piece of information is the building working time. Table A1 in the Appendix presents a very useful classification based on European Committee for Standardization (2002), of use to technicians for the definition of this parameter.

The perspective of the decision-maker defines basic parameters that will drive the decision. In this study, as discussed in the previous section, the purpose of the model is to measure the contribution of each project to the sustainable development the region. Consequently, the main axes of the decision tree 
(section 2.2) will be: society, environment and economy, which are the three main axes of sustainable development.

\section{2.- Sustainable Building index $\left(\mathrm{B}_{\mathrm{s}}\right)$ : The requirements tree}

The decision tree for assessing the Sustainable Building index $\left(B_{s}\right)$ is presented in this section (see figure 1). The tree consists of three requirements $(\mathrm{R})$, four criteria $(\mathrm{C})$ and thirteen indicators $(\mathrm{I})$. The indicators are the only concepts that are evaluated; a task done with qualitative and quantitative variables and different units and scales. The indicators were selected in an attempt to assess the most important and significant characteristics of public buildings.

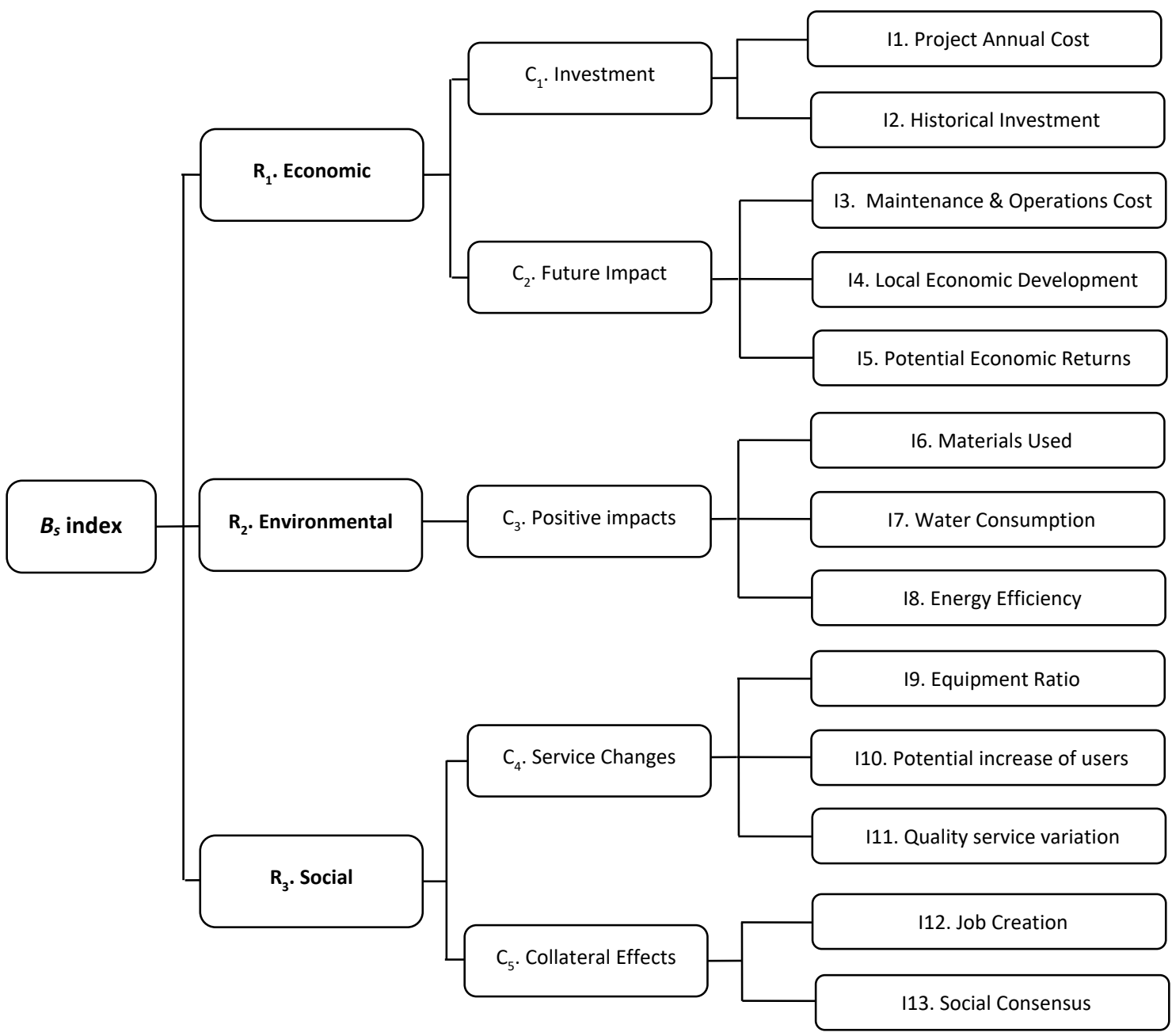

Figure 1.- Decision tree for Sustainable Building index $\left(B_{s}\right)$ with the relative weights of each component 


\subsubsection{Economic requirement}

The economic requirement $\left(R_{1}\right)$ is represented by two criteria: Investment $\left(C_{1}\right)$ and Future impacts $\left(C_{2}\right)$. Investment criteria are divided into two indicators: Project Annual Cost and Historical Investment; while Future Impacts are sub-divided into three categories: Maintenance \& Operating Costs, Local Economic Development, and Potential Economic Returns.

Project Annual Cost $\left(I_{1}\right)$ : an indicator with which to assess the importance of the initial investment to construct a building. It links this cost with the service life of the building (its working life, $\mathrm{W}_{\mathrm{L}}$ ), as shown in Eq. (1). This ratio benefits high-level investments, which usually finance buildings that will be in operation over many years.

$$
\mathrm{I} 1=\frac{\text { Initial Investment }}{\mathrm{W}_{L}}
$$

Historical Investment $\left(I_{2}\right)$ : based on concepts advanced in Pardo-Bosch and Aguado (2016), this concept is an attempt to redress investment imbalances by promoting the construction of buildings in areas where investment has been low over the past ten years. It thereby promotes development, because, as Mori and Christodoulou (2012) pointed out, social sustainability has to be based on equal opportunities. The degree of investment is calculated by relating the investment with population, area and GDP, as shown in Eq. (2). The higher the historical investment, the lower the score.

$$
I 2=\left(\frac{\frac{I_{Z}}{I_{T}} 100}{\frac{P_{Z}}{3 P_{T}}+\frac{E_{Z}}{3 E_{T}}+\frac{G_{Z}}{3 G_{T}}}\right)
$$

where, I represents public investment in infrastructures over the past ten years; $P$ is the population; $E$ is the area; and, $G$ is the Gross Domestic Product. Sub-index $Z$ refers to the zone where the new building would be located, and sub-index $T$ refers to the whole territory. 
Maintenance \& Operations Cost $\left(I_{3}\right)$ : an indicator with which to assess (only the regular) annual project conservation costs payable by the public administration, to ensure that the building is maintained under operating conditions, as recommended by Ziara et al. (2002).

Local Economic Development $\left(I_{4}\right)$ : measures the direct contribution of a new building to the local economy. This indicator has regularly been considered in the evaluation of transport projects, as may be seen in Berechman and Paaswell (2005) and Tsamboulas (2006). The more people travel to a new facility, the more it stimulates the local economy. This indicator is evaluated by attributes sub-divided into 3 categories: no economic development (1 points); marginal economic development (3 points), a boost for the local economy (5 points).

Potential Economic Returns ( $\left.I_{5}\right)$ : an indicator that assesses the potential revenue that a new building can directly generate because of its activities (tickets for a museum and school fees) or indirectly (sale of surplus energy, rental of floor space...). This variable is evaluated by attributes in 3 categories: nonrevenue (1 points), sporadic revenue (3 points); recurrent revenue (5 points).

\subsubsection{Environmental requirement}

When a building is constructed in an urban area, no Environmental Impact Evaluation (United States Congress, 1969) is needed, because its construction in an uban area is not considered to harm the natural environment. In these cases, the Environmental requirement $\left(R_{2}\right)$ may be used by public administrations to promote active environmental policies. Therefore, this requirement is represented by one single criterion: Positive impacts $\left(\mathrm{C}_{3}\right)$, divided into three indicators: Materials Used, Water Consumption, and Energy Efficiency.

Materials Used $\left(I_{6}\right)$ : measures the type of construction materials used in the construction process, placing special stress on the use of sustainable and renewable materials, as recommended by Liu et al. (2015). This indicator is assessed through three variables: recycled materials (RM), use of local materials (LM), and the non use of limited materials (NLM), which are related by Eq. (3). Each variable is evaluated by attributes under 3 categories: Regular Use (5 points), Sporadic Use (3 points) and No Use (1 point). 
Water Consumption ( $\left.I_{7}\right)$ : an indicator that evaluates active policies for reducing water consumption in the service life of a building. It is assessed with the following variables: Rainwater harvesting (RH), devices to reduce water use (toilets with dual push button, faucet aerators) (RWU), tanks with greywater reuse (TGW), reuse of irrigation water and efficient irrigation systems (EIS). All those variables are assessed by Yes (1 point) or No (0 points) and they are related as shown in Eq. (4).

$$
17=\mathrm{RH}+\mathrm{RWU}+\mathrm{TGW}+\mathrm{EIS}
$$

Energy Efficiency $\left(I_{8}\right)$ : evaluates active policies on energy. The indicator consists of two variables: holding an Energy Performance Certificate (EPC), as defined by the European Parliament (2010), and Energy Production (EP). The value assigned to the Energy Performance Certificate variable is directly dependent on the category under which the building is classified: $A(7 p), B(6 p), C(5 p), D(4 p), E(3 p), F(1 p), G(1 p)$. It is important to recall that this variable implicitly evaluates the $\mathrm{CO}_{2}$ emissions of each building. Moreover, the Energy Production variable is evaluated by attributes in 3 categories: no energy production (1 points); production only for self-consumption (3 points); surplus energy produced (5 points). The two variables are related by a summation as shown in Eq. (5).

$18=E P C+E P$

The approach to assess the indicators of this requirement represents an initial approximation. It can eventually be as complex as the laws of any one country may require. In addition, it is important to note the possibility of using the results of specific environmental studies (such as an LCA) without major problems. 


\subsubsection{Social requirement}

The social requirement $\left(R_{3}\right)$ is represented by two criteria: Service Changes $\left(C_{5}\right)$ and Collateral Effects $\left(C_{6}\right)$. Service Changes is sub-divided into three indicators: Equipment Ratio, Potential increase of users and Quality service variation, while Collateral Effects is only sub-divided into two indicators: Job Creation and Social Consensus.

Equipment Ratio $\left(I_{g}\right)$ : assesses the need for a new building that will offer a particular kind of service. This indicator is calculated through a ratio between the number of existing buildings that offer the same service and the theoretical number that the authorities have planned (see Eq. 6). The lower the ratio, the higher the need for the building.

$$
\text { I9 }=\frac{\text { Existing Buildings }}{\text { Necessary Buildings }}
$$

Potential increase of users $\left(I_{10}\right)$ : evaluates, in percentage terms, the number of new users who could access a service from the new building. If the service was not yet offered, or if it is offered at a building in another city, then the value of this indicator will be $100 \%$.

$$
\mathrm{I} 10=\frac{\Delta \text { num. users }}{\text { old num. users }} \cdot 100
$$

Quality service variation $\left(I_{11}\right)$ : assesses how the level of the service that is offered will be increased by the new building. It is a very important parameter, especially for buildings which will replace old buildings already offering that service. The evaluation is sub-divided into 5 categories: no improvement (1 point), marginal improvement ( 2 points); improvement (3 points); significant improvement (4 points), and very important improvement (5 points).

Job Creation ( $\left.I_{12}\right)$ : this indicator, as recommended in Lambert et al. (2012) and Veldhuizen et al. (2015), is an attempt to assess the number of new jobs that would be directly created as a consequence of the new Building (eq. 8). Job Creation will take into account the jobs that will be created during the construction 
(CJ), and the jobs created during the service life of the building (EJ). CJ will be relativized according to the construction duration (CD) and the service life of the building (SL), as recommended in Pardo-Bosch and Aguado (2016).

$$
\mathrm{I} 11=\mathrm{EJ}+\frac{\mathrm{CD}}{\mathrm{SL}} \mathrm{CJ}
$$

Social Consensus (I13): evaluates the specific acceptance of projects by local stakeholders, particularly residents and local authorities (Wüstenhagen et al., 2007). The evaluation takes place through attributes placed in 5 categories: absolute rejection (1 point); rejection by a part of society ( 2 points); indifference (3 points); support from a part of society (4 points), and absolute support (5 points).

\subsection{Value Functions}

Each indicator in the decision tree requires a value function, to obtain a final value, allowing the standardization of the different units involved in the assessment of the building projects (Alarcon et al., 2011). These value functions were defined by consensus among a panel of experts. The chosen value function depends on five parameters that allow the representation of the most usual forms: "S-shaped", concave, convex and linear. Then the value function for the case of a decreasing function, followed by the definition of the parameters on which it depends, is shown in equation 9.

$$
V\left(I_{x}\right)=B \cdot\left[1-e^{-K i \cdot\left(\frac{|X-X m i n|}{C i}\right)^{P i}}\right] \quad\left(\text { Eq. 9) } \quad B=\left[1-e^{-K i \cdot\left(\frac{|X \max -X \min |}{C i}\right)^{P i}}\right]^{-1}\right.
$$

In the previous equation, $\mathrm{X}_{\max }$ is the maximum abscissa of the interval for the indicator that is evaluated (in increasing functions the resulting value is 1 ). $X$ is the abscissa of the indicator under evaluation (different or otherwise, for each alternative) that generates a value equal to $\mathrm{V} . \mathrm{P}_{\mathrm{i}}$ is a factor that defines whether the curve is concave, convex or linear in an "S-shape". Concave curves are obtained for values of $P_{i}<1$, convex or "S-shaped" if $P_{i}>1$ and linear curves for $P_{i}=1$ values. Moreover, $P_{i}$ roughly determines the slope of the curve at the inflection point. $C_{i}$ approximates the $x$-value of the point of inflexion for curves with $P_{i}>1$, while Ki approximately defines the $y$-value at point $C_{i}$. B is the factor that allows the function to be maintained in the range of values from 0 to 1 ; a factor that is defined by equation 10 . For 
decreasing functions, which have their maximum value in $X_{\min }$, the parameter $X_{\min }$ in equation 9 should be replaced by $X_{\max }$, where $X_{\max }$ is the minimum abscissa of the value interval for the indicator that is evaluated. The parameter values for the value functions of all the indicators of the decision tree are presented in the table 1.

Table 1.- Value function parameters for each indicator

\begin{tabular}{ccccccc}
\hline & $X_{\min }$ & $X_{\max }$ & $C$ & $K$ & $P$ & Shape \\
\hline I1 & 0 & 200.000 & 120.000 & 1 & 2 & $S(d)$ \\
$I 2$ & -15 & 30 & 10000 & 1 & 1 & Linear \\
I3 & 20.000 & 350.000 & 150.000 & 0.2 & 3 & $S(d)$ \\
I4 & 1 & 5 & 100.000 & 1 & 1 & Linear \\
I5 & 1 & 5 & 100.000 & 1 & 1 & Linear \\
I6 & 3 & 15 & 5 & 1 & 2 & $S$ \\
I7 & 0 & 4 & 100.000 & 1 & 1 & Linear \\
I8 & 2 & 12 & 100.000 & 1 & 1 & Linear \\
I9 & 0 & 1.5 & 1 & 0.5 & 2 & Convex (d) \\
I10 & 0 & 100 & 100.000 & 1 & 1 & Linear \\
I11 & 1 & 5 & 10.000 & 1 & 1 & Linear \\
I12 & 0 & 40 & 20 & 1 & 2 & $S$ \\
I13 & 1 & 5 & 1000 & 0.3 & 1 & Linear \\
\hline
\end{tabular}

(d) = decreasing

\subsection{Indicator weights}

With the MIVES method, AHP is usually applied at each level of the decision tree, in order to calculate the weights of the different components at each level, because the final result is calculated with the sum of the value of each indicator, $I V_{j}\left(P_{i, x}\right)$, weighted at three levels, integrating the relative weight of each indicator, criteria and requirement. The weight of the requirements was directly assigned by the panel of experts: 35\% Economic r., 20\% Environmental r. and 45\% Social r. In this case, the authors decided to use AHP (Saaty, 1980) to assess at the same time, with only one pairwise matrix, all the indicators of the same requirement, without taking their criteria into account. Two pairwise matrices, " $\mathrm{M}$ " and " $\mathrm{N}$ " based on $\mathrm{AHP}$, are presented in Eq. 11 and Eq. 12. Both matrices are considered consistent and are necessary, in order to calculate the importance of each of the economic indicators, vector "V", and the importance of each of the social indicators, vector "W", which are, respectively, presented in Eq. 13 and Eq. 14 (matrix eigenvalues). 
$\mathrm{M}=\left(\begin{array}{cccccc}5 \mathrm{x} 5 & \mathrm{I} 1 & \mathrm{I} 2 & \mathrm{I} 3 & \mathrm{I} 4 & \mathrm{I} \\ \mathrm{I} 1 & 1.00 & 2.00 & 4.00 & 5.00 & 5.00 \\ \mathrm{I} 2 & 0.50 & 1.00 & 1.00 & 2.00 & 2.00 \\ \mathrm{I} 3 & 0.25 & 1.00 & 1.00 & 3.00 & 3.00 \\ \mathrm{I} 4 & 0.20 & 0.50 & 0,33 & 1.00 & 1.00 \\ \mathrm{I} 5 & 0.20 & 0.50 & 0,33 & 1.00 & 1.00\end{array}\right) \quad(11) \quad \mathrm{N}=\left(\begin{array}{cccccc}5 \mathrm{x} 5 & \mathrm{I} 9 & \mathrm{I} 10 & \mathrm{I} 11 & \mathrm{I} 12 & \mathrm{I} 13 \\ \mathrm{I} 9 & 1.00 & 1.00 & 2.00 & 3.00 & 3.00 \\ \mathrm{I} 10 & 1.00 & 2.00 & 2.00 & 3.00 & 3.00 \\ \mathrm{I} 11 & 0.50 & 0.50 & 1.00 & 2.00 & 2.00 \\ \mathrm{I} 12 & 0.33 & 0.33 & 0,50 & 1.00 & 1.00 \\ \mathrm{I} 13 & 0.33 & 0.33 & 0,50 & 1.00 & 1.00\end{array}\right)$

$\mathrm{V}=\left(\begin{array}{l}0.46 \\ 0.21 \\ 0.16 \\ 0.08 \\ 0.08\end{array}\right) \quad(13) \quad \mathrm{W}=\left(\begin{array}{l}0.31 \\ 0.31 \\ 0.16 \\ 0.10 \\ 0.12\end{array}\right)$

With the requirement weights that were previously presented, and with vectors " $\mathrm{V}$ " and " $\mathrm{W}$ ", it is possible to calculate the relative weight of the remaining elements of the decision tree (criteria and indicators), as well as the total weight of each indicator. Those values are presented in table 2: RRW stands for Requirement Relative Weight, CRW stands for Criteria Relative Weight, IRW for Indicator Relative Weight, and, finally, ITW for Indicator Total Weight. The relative weight of the indicators of the environmental requirement are each 33.3\%, following the advice from the panel of experts that considered all of them of similar relevance.

Table 2.- Weights of decision tree components calculated by AHP

\begin{tabular}{|c|c|c|c|c|c|c|c|c|c|c|c|c|c|}
\hline $\mathrm{R}_{\mathrm{RW}}(\%)$ & \multicolumn{5}{|c|}{$\mathrm{R}_{1}=35$} & \multirow{2}{*}{\multicolumn{3}{|c|}{$\begin{array}{l}\mathrm{R}_{2}=20 \\
\mathrm{C}_{3}=100\end{array}$}} & \multicolumn{5}{|c|}{$\mathrm{R}_{3}=45$} \\
\hline $\mathrm{C}_{\mathrm{RW}}(\%)$ & \multicolumn{2}{|c|}{$C_{1}=62$} & \multicolumn{3}{|c|}{$C_{2}=38$} & & & & \multicolumn{3}{|c|}{$C_{4}=78$} & \multicolumn{2}{|c|}{$C_{5}=22$} \\
\hline$I_{R W}(\%)$ & $I_{1}=74$ & $I_{2}=26$ & $I_{3}=56$ & $I_{4}=22$ & $I_{5}=22$ & $I_{6}=33.3$ & $I_{7}=33.3$ & $I_{8}=33.3$ & $I_{9}=40$ & $I_{10}=40$ & $I_{11}=20$ & $I_{12}=45$ & $I_{13}=55$ \\
\hline ITW (\%) & $I_{1}=16.0$ & $I_{2}=5.5$ & $I_{3}=7.5$ & $\mathrm{I}_{4}=3.0$ & $I_{5}=3.0$ & $I_{6}=6.6$ & $I_{7}=6.6$ & $I_{8}=6.6$ & $I_{9}=14.0$ & $I_{10}=14.0$ & $I_{11}=7.0$ & $I_{12}=4.5$ & $I_{13}=5.5$ \\
\hline
\end{tabular}

In that context, it was interesting to compare the total weights of the indicators shown in table 2 (which were obtained by AHP) with the weight that would be obtained, if a direct weight had been assigned to each component of the tree (requirements, criteria and indicators). To that end, the assistance of the panel of experts was requested and the results are presented in table 3 (in this case, the subscripts are replaced by superscripts, to avoid confusion). 
Table 3.- Weights of decision tree components determined by direct assignation

\begin{tabular}{|c|c|c|c|c|c|c|c|c|c|c|c|c|c|}
\hline $\mathrm{R}^{\mathrm{RW}}(\%)$ & \multicolumn{5}{|c|}{$R_{1}=35$} & \multirow{2}{*}{\multicolumn{3}{|c|}{$\begin{array}{l}\mathrm{R}_{2}=20 \\
\mathrm{C}_{3}=100\end{array}$}} & \multicolumn{5}{|c|}{$R_{3}=45$} \\
\hline $\mathrm{C}^{\mathrm{RW}}(\%)$ & \multicolumn{2}{|c|}{$C_{1}=60$} & \multicolumn{3}{|c|}{$C_{2}=40$} & & & & \multicolumn{3}{|c|}{$C_{4}=70$} & \multicolumn{2}{|c|}{$C_{5}=30$} \\
\hline $\mathrm{I}^{\mathrm{RW}}(\%)$ & $I_{1}=70$ & $\mathbf{I}_{\mathbf{2}}=30$ & $I_{3}=50$ & $I_{4}=25$ & $I_{5}=25$ & $I_{6}=33.3$ & $I_{7}=33.3$ & $I_{8}=33.3$ & $I_{9}=40$ & $I_{10}=40$ & $I_{11}=20$ & $I_{12}=40$ & $I_{13}=60$ \\
\hline $\mathrm{I}^{\mathrm{TW}}(\%)$ & $I_{1}=14.5$ & $I_{2}=6.5$ & $I_{3}=7.0$ & $\mathrm{I}_{4}=3.5$ & $I_{5}=3.5$ & $I_{6}=6.6$ & $I_{7}=6.6$ & $I_{8}=6.6$ & $I_{9}=12.5$ & $I_{10}=12.5$ & $I_{11}=6.5$ & $I_{12}=5.5$ & $I_{13}=8.0$ \\
\hline
\end{tabular}

If the values of table 2 and 3 are compared, especially the total weight of each indicator (ITW and IW respectively), it is possible to see that the difference between them is quite small. Indicator I13 presents the highest variation of around $2.5 \%$. Both systems, therefore yielded equivalent results in this case. The combination obtained with AHP was used to calculate the Building Sustainability index ( $\left.B_{s}\right)$, due to the fact that it was considered more objective. Hence, the $B_{s}$ for each building was calculated with the sum of each indicator value, $I V_{i}\left(P_{x}\right)$, multiplying each one by its own total weight (ITW $\left.\mathrm{T}_{\mathrm{i}}\right)$, as shown in Eq. (11).

$$
\operatorname{Bs}\left(\mathrm{P}_{x}\right)=\sum_{i=1}^{i=13} \mathrm{ITW}_{\mathrm{i}} \cdot \mathrm{IV}_{\mathrm{i}}\left(\mathrm{P}_{x}\right)
$$

If the reader analyses the weight of the requirements, the importance of the social requirement (representing approximately $45 \%$ of the decision) can be appreciated, even if the most significant indicator is the Project Annual Cost (16\%), which is the first indicator of the economic requirement, closely followed by Potential Increase of Users and Equipment Ratio, both from the social requirement. These differences are very understandable, because most developed countries are undergoing a severe economic crisis, with very limited resources for this kind of project. Although the weights presented in table 2 were used in the main analysis of this methodology, in section 4.1 , the authors will present a sensitivity analysis of the weightings that reflects other reasonable scenarios that could also be considered by another panel of experts.

\section{Case Study}

A case study was conducted in which 4 projects of public building in Catalonia were assessed, in a test of the effectiveness of the proposed method. Spain has undergone a very harsh period of austerity over the past few years, which obliged public administrations to control their budgets very tightly in an adverse 
economic situation. The Sustainable Building index $\left(B_{s}\right)$ is therefore very advantageous, because of the imperative need to justify the construction of new public buildings. In that context, Infraestructures de la Generalitat de Catalunya S.A.U, a public company of the Generalitat de Catalunya, fully aware of these issues and the usefulness of this type of tool, participated in $B_{s}$ development and allowed the authors to apply it to four real projects. These projects, with an assigned working life of 50 years, are described below.

Medical Centre $\boldsymbol{A}(\boldsymbol{P} 1)$ : construction project $\left(3,000 \mathrm{~m}^{2}\right)$ to provide primary health care service to a population of approximately 35,000 . In addition, the facility will provide services for mental and reproductive health which are currently not available in the city. A further objective is to centralize pediatric services. The city has two other similar centres that are struggling to respond to rising demand. Cost: € 5.1 million.

Medical Centre $\boldsymbol{B}(\mathbf{P 2})$ : construction project $\left(1,800 \mathrm{~m}^{2}\right)$ to provide primary health care services to a population of approximately 15,000 . As the reference centre in the area, the facility will offer an emergency service to residents of 5 municipalities. The opening of the new facility will coincide with the closure of the old centre, which it will replace. Cost: $€ 3.2$ million

Police Station $(\mathbf{P} 3)$ : construction project $\left(1,500 \mathrm{~m}^{2}\right)$ of a police station for the local Catalan police force (40 law enforcement agents) to provide services to a population of approximately 20,000 people, distributed throughout 5 municipalities, within a radius of approximately $450 \mathrm{~km}^{2}$. The significant presence of tourists in what is largely a coastal area increases the population over the summer months. Moreover, there is a confluence of some important roads with considerably high accident rates. The nearest police station is at present over $30 \mathrm{~km}$ away. Cost: $€ 2.5$ million.

School (P4): construction project $\left(2,500 \mathrm{~m}^{2}\right)$ for an educational centre offering nursery and primary education. The city has other similar centres, but with this facility the educational offer would be increased by $15 \%$. In addition, its construction will mean a regular service can be provided, unlike the current situation of a school functioning in temporary structures located within the playing fields of another school. Cost: €3.7 million 
The scores of the indicators and their final value (0-1) after applying the value function are shown in Table $\mathrm{A} 2$ in the Appendix. If there is more than one variable to value an indicator, the table specifies the score for each one. The data for the evaluation of the indicators were obtained from public documents and the construction project of each building. When projects had no information on a particular variable, the authors decided to penalize that indicator by assigning it the lowest possible score. The last row of table A2 presents the final result of $B_{s}$.

Figure 2 presents, for each of the 4 projects, the value (from 0 to 1 ) of each indicator, before applying its weight. It is easily seen that the value of each indicator varies significantly depending on the project. This variation is important, in order to see the importance of all the indicators and the differences between projects. Had one indicator obtained the same score for all the projects under assessment, then that indicator would hardly have been relevant for the prioritization of projects, making it advisable to remove it from the decision tree, despite it measuring very significant data.

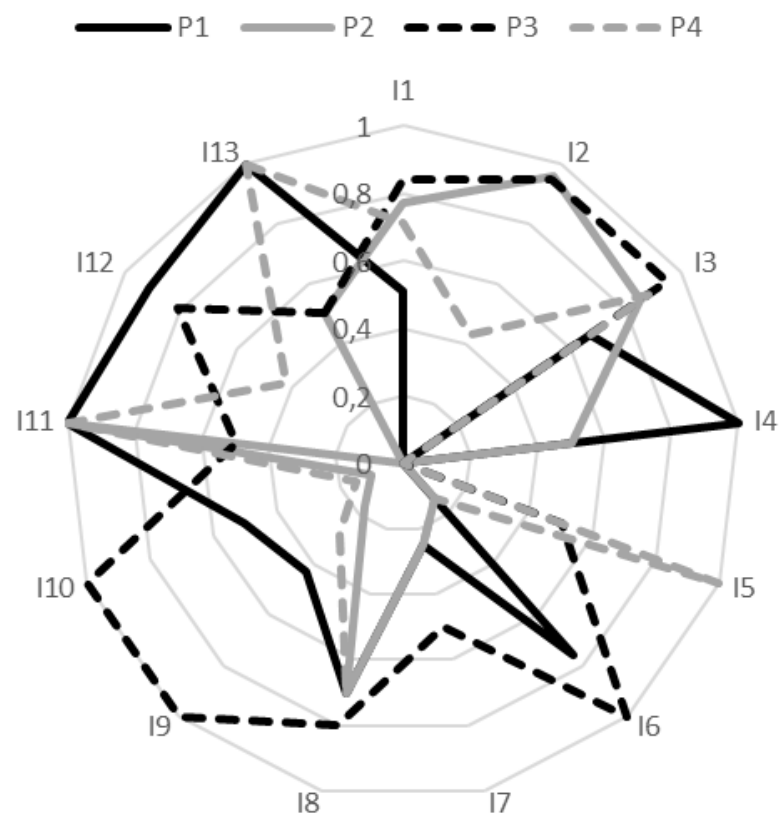

Figure 2.- Indicator values (from 0 to 1) for each project

Figure 3 a shows a spider graph of the result, in which the classification of the projects with the $B_{s}$ index may easily be seen. In this case study, the project with the best $B_{s}$ is P3 (Police Station), followed by P1 
(Medical Centre A), and finally P2 (Medical centre B). In figure 3b, it is possible to see the value of the three dimensions of sustainability for each project, adding up the value of the indicators under the corresponding requirement (see figure 1), each multiplied by its own weight. This figure also gives an idea of how far each solution is from the maximum score for each requirement. It likewise makes it possible to understand which requirement gives a competitive advantage to one project over and against the others.

a)

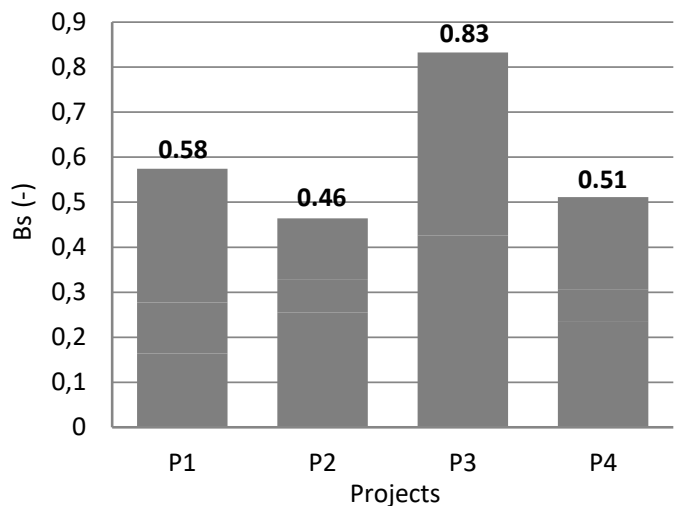

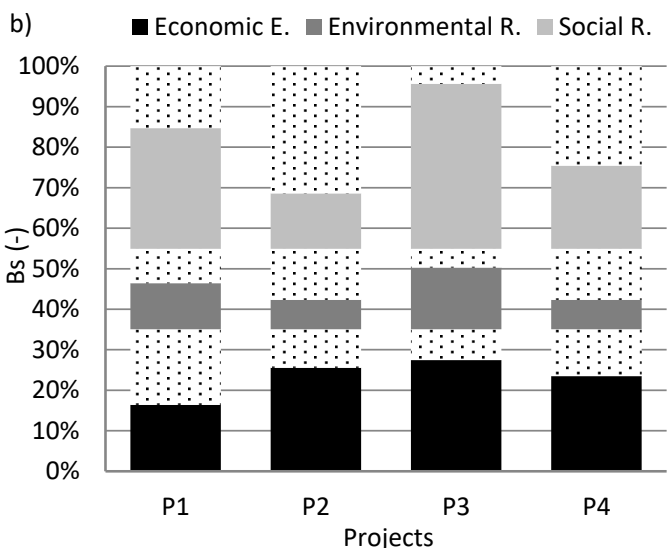

Figure 3.- $B_{s}$ (from 0 to 1) for each project

P3 is the best project according to $B_{s}$. This project not only obtained the highest $B_{s}$, but it also obtained the highest score for each requirement, so it is clearly the most complete project. If readers analyse the project classified in second place, P1, they can appreciate that it was penalized by the economic requirement, achieving less than half the maximum score. However, the most important information that figure 3 shows us is that the methodology produces a useful classification of public building projects, generating a sufficiently large range of scores (between $0.45-0.85$ ) to discriminate between them. It is very difficult for a project to be attributed a value of 1 , which would imply a "perfect" project. It is also very difficult to find a project with a score lower than 0.2 , given that public administrations normally discard those projects automatically, because of their lack of usefulness.

\section{Discussion}

This section is divided into two large blocks; the first one describes a sensitivity analysis of the results of changing the weight of the requirements, and the second compares the results obtained by $B_{s}$ with the theoretical results that other methodologies would obtain, if they were used to assess the projects presented in section 3 . 


\section{1.- Sensitivity analysis}

This section aims to analyse the sensitivity of the methodology that has been developed, as previously mentioned. The authors changed the Original Weight (OW) of the three requirements to establish three different alternative combinations. In $\mathrm{A} 1$, the weight of social requirement rose to $60 \%$, the remaining $40 \%$ was divided into two equal parts between Economic and Environmental Requirements. In A2, all requirements have the same weight, i.e. $33.3 \%$. Finally, in $A 3$, the most important part of the decision (80\%) falls into the economic requirement, and the remaining $20 \%$ is divided into the other two requirements. Alternatives $\mathrm{A} 1$ and $\mathrm{A} 2$ are two combinations of weights considered consistent. Alternative A3 could be described as an absurd combination.

Figure 4 shows the value of the index obtained for each project depending on the alternative under study. Alternatives $\mathrm{A} 1$ and $\mathrm{A} 2$ presented very similar results to the initial study. The variations of weights in both cases were insignificant, so the final results were, as expected, very similar to the original one. However, the result of $A 3$ was significantly different from the original one. In $A 3$, the Economic requirement had a predominant weight, and its most important indicator was I1 (Project Annual Cost), which accumulated $40 \%$ of the decision. It was understandable that the cheapest projects (P2 and P3) were classified at the top. The $B_{s}$ of P3 underwent very little change, as a sound project with good qualifications in almost all the indicators (see figure 1), so its score was never far off one, regardless of the distribution of the weights. However, the combination of weights in A3 significantly changed the classification of the projects. P2 passed from the final to the second position; while P1 passed from the second to the last position. The results obtained from the tree configuration of weights show the robustness of the tool that maintains the results if the changes are minimal and changes the results whenever the variations are significant. 


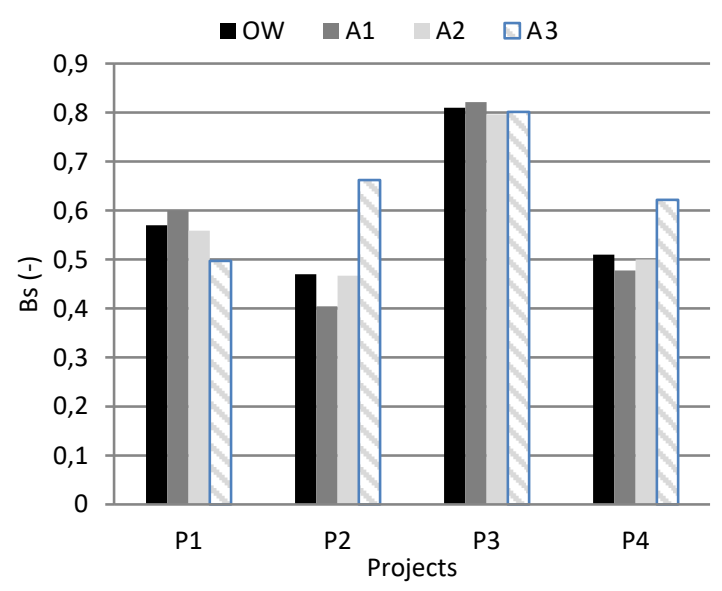

Figure 4.- $B_{s}$ value for each project and each alternative

\subsection{Comparison with other methodologies}

The projects presented in section 3 were analysed with another two methodologies used for infrastructure prioritization, to test the effectiveness of $B_{s}$. The first one was presented in de Ziara et al. (2002), the result of which is the Priority Vector; and the second one was presented in Pardo-Bosch and Aguado (2016), the result of which is SIIP. As there is no specific model to assess buildings, these two methodologies, which have been used to analyse public buildings, were selected on the understanding that buildings are public infrastructures. The tool advanced by Ziara et al. (2002) is based on AHP; while Pardo-Bosch and Aguado presented a MIVES-based tool, as in this paper. However, SIIP divides the assessment into two phases, which makes the process much more complicated and lengthier, and unnecessary if projects are homogenous, as in this case. The scope is not to compare the numeric results of each index, since MIVES and AHP use different scales. The objective is to compare the prioritization that each methodology defines.

In table 4, the value of each indicator is presented for each project obtained by Ziara et al. (2002), as well as the Priority Vector, which shows the prioritization of this methodology. Likewise, table 5, shows the value of each indicator obtained by Pardo-Bosch and Aguado (2016), as well as the SIIP. 
Table 4.- Indicators values and final result using the Priority Vector of Ziara et. al. (2002)

\begin{tabular}{ccccccccc}
\hline & 11 & 12 & 13 & 14 & 15 & 16 & 17 & Priority Vector \\
\hline P1 & 0.24 & 0.22 & 0.14 & 0.10 & 0.14 & 0.25 & 0.25 & 0.19 \\
P2 & 0.07 & 0.22 & 0.14 & 0.16 & 0.14 & 0.25 & 0.13 & 0.15 \\
P3 & 0.54 & 0.11 & 0.45 & 0.47 & 0.45 & 0.25 & 0.50 & 0.40 \\
P4 & 0.15 & 0.44 & 0.26 & 0.28 & 0.26 & 0.25 & 0.13 & 0.26 \\
\hline
\end{tabular}

$11=$ Project importance; $12=$ Sector importance; $13=$ =Finance suitability; $14=$ Execution suitability; $15=$ Operation suitability; 16= Reliability; $17=$ Consequence of failure

Table 5.- Indicators values and final result using SIIP (Pardo-Bosch \& Aguado, 2016)

\begin{tabular}{cccccccccc}
\hline & 11 & 12 & 13 & 14 & 15 & 16 & 17 & 18 & SIIP \\
\hline P1 & 0.94 & 0,20 & 0.22 & 0.88 & 0.20 & 0.42 & 0.22 & 1 & 0.56 \\
P2 & 0.97 & 0.50 & 0.22 & 0.58 & 0.18 & 0 & 0.03 & 0.75 & 0.47 \\
P3 & 0.98 & 0.58 & 0.22 & 0.88 & 0.52 & 0.81 & 0.15 & 1 & 0.75 \\
P4 & 0.96 & 0.24 & 0.41 & 0.36 & 0.27 & 0.58 & 0.27 & 0.75 & 0.50 \\
\hline
\end{tabular}

$11=$ Annual Unitary Cost; $12=$ Recurring Cost; $13=$ Investment Profit; $14=$ Impact Rank; $15=$ Quality Change; $16=$ Capacity Change; 17= Job Creation; 18= Social Agreement

The three methodologies obtained similar results, the highest priority Project was P3, while the lowest priority was P2. The system proposed by Ziara et al. (2002) classified P4 in second place, while both of the MIVES-based models placed it in $3^{\text {rd }}$ position. Likewise, numerical results obtained by SIIP and Bs are very similar. All these arguments validate the methodology presented in this paper. Furthermore, the most comprehensive evaluation of the projects was done with the Sustainable Building index $\left(B_{s}\right)$ rather than with the other two methodologies, without the simplicity of the Priority Vector or the complexity of SIIP.

\section{6.- Conclusions}

In the era of big data, making decisions without measuring is a luxury that smart cities can not afford to contemplate. Promoting urban sustainability, as has seen described in this paper, represents a great challenge for cities and their managers. Buildings for public services are ideal targets to start implementing decision-making methodologies to ensure a positive balance in terms of social inclusion, conservation of the environment and economic viability. Sustainability assessment has to become an essential part of any smart city strategic plan, as a smart city is a sustainable city. Therefore, public managers should help to promote smart sustainable cities, which is the objective supported by this study and others like it, rather than the smart-city concept. 
In view of that principle, the contribution of this paper is twofold. From an academic perspective, it contributes to the existing literature on the assessment of urban sustainability developing a multi-criteria decision-making methodology (Building Sustainable Index, Bs) for the evaluation of projects related to public buildings that are not easily compared such as hospitals, schools, museums, hospitals, etc., minimizing subjectivity in the entire decision-making process. This feature makes $B_{s}$ a very innovative system, correcting the lack of scientific studies in this field. The decision tree guarantees a very exhaustive and complete assessment of each project. Moreover, no complex software is necessary, as the model can be implemented on a spreadsheet. In this study, the application of AHP for the first time at criteria level, rather than at indicator level, unlike other research studies, introduces remarkable improvements to the objectivity of this tool. From a managerial point of view, this paper offers public managers a tool that will help them to prioritize investment according to clear, consistent, and transparent criteria, while ensuring the sustainable development of their regions, thereby building bridges between researchers and practitioners.

Those institutions that decide to use $B_{s}$ will introduce new rules on the decision-making processes in their cities. $B_{s}$ will allow public managers to justify their decisions, showing their citizens why they are making that decision, and thereby offering transparency and accountability. Moreover, $\mathrm{B}_{\mathrm{s}}$ will promote consensus among different political parties. Since the decision tree and their weights are defined beforehand, with the participation of all key stakeholders and decision makers, discussion over the outcome of any $\mathrm{B}_{\mathrm{s}}$-based prioritization will be unlikely.

The elements that constitute the methodology are perfectly defined, ensuring traceability so that $B_{s}$ can be used by any public institution. It would be only necessary to change the weights of the components of the decision tree, in order to adapt them to the criteria of "new" decision makers. The robustness shown in the sensitivity analysis and the comparison with other methodologies guarantee the applicability of $B_{s}$ in other cities.

The case study produced very satisfactory results, showing that accurate and consistent assessments can be generated with this methodology. The results of $B_{s}$ clearly differentiate projects, as shown by the coefficient of variation ( $C V=0.27$ ) of the case study, which is higher than 0.25 (Morales 2008). This categorization of the merits of one or another project on the basis of pre-defined criteria is especially 
based on the following indicators: Historical Investment, Materials Used, Equipment Ratio, Potential Increase of Users, and Job Creation.

Finally, the fact that the authors assessed only four real projects, in view of the difficulties over access to this type of confidential project, could be considered a limitation. The study could also be improved upon in future research by introducing fuzzy logic that would approximate responses to the inherent uncertainty in these kinds of assessments. Future studies could introduce in their decision trees indicators to measure the intangible resources generated by the projects in terms of social capital taking into account how a public building can increase the human capital, the structural capital and also the relational capital of one society.

\section{Acknowledgments}

Authors want to acknowledge the collaboration that they have received from Infraestructuras de la Generalitat de Catalunya S.A.U., a Generalitat de Catalunya public company represented by Jordi Joan Rossell, Joan Serratosa and August Varela. Authors also want to recognize the work done by Joan Compte, Francisco Guarner, Alejandro Josa from UPC (Barcelona Tech). Finally, authors acknowledge the support of Projects BIA2013-49106-C2-1-R and BIA2016-78742-C2-1-R of the Ministerio de Ciencia $y$ Competitividad (Spain).

\section{References}

Addanki, S. C., \& Venkataraman, H. (2017). Greening the economy: A review of urban sustainability measures for developing new cities. Sustainable Cities and Society, 32, 1-8. doi.org/10.1016/j.scs.2017.03.009

Aguado, A., del Caño, A., de la Cruz, P., de la Cruz, P., Gómez, P. and Josa, A. (2012). Sustainability assessment of concrete structures. J. Constr. Eng. M ASCE, 138: 268-276. doi: 10.1061/(ASCE)CO.19437862.0000419, 268-276.

Ahmad, T., \& Thaheem, M. J. (2018). Economic sustainability assessment of residential buildings: A dedicated assessment framework and implications for BIM. Sustainable Cities and Society (Vol. 38). doi.org/10.1016/j.scs.2018.01.035

Ahvenniemi, H., Huovila, A., Pinto-Seppä, I., \& Airaksinen, M. (2017). What are the differences between sustainable and smart cities? Cities, 60, 234-245. doi.org/10.1016/j.cities.2016.09.009

Alarcón, B., Aguado, A., Manga, R. and Josa, A. (2011). A Value Function for Assessing Sustainability: Application to Industrial Buildings. Sustainability, 3(1): 35-50. doi:10.3390/su3010035. 
Alcaraz-Quiles, F.J., Navarro-Galera, A. and Ortiz-Rodríguez, D. (2014). Factors influencing the transparency of sustainability information in regional governments: an empirical study. Journal of Cleaner Production, 82, 179-191. doi:10.1016/j.jclepro.2014. 06.08.

Ascione, F., Bianco, N., De Masi, R.F., de'Rossi, F. \& Vanoli, G.P. (2015). Energy retrofit of an educational building in the ancient center of Benevento. Feasibility study of energy savings and respect of the historical value. Energy Build. 95, 172-183.

Balali, V., Zahraie, B., Hosseini, A. and Roozbahani, A. (2010). Selecting the appropriate structural system by application of PROMETHEE decision making method. Proceedings of 2 nd IEE international conference on system engineering and application, Sharjah, UAE, 1-6.

Banani, R., Vahdati, M. M., Shahrestani, M., \& Clements-Croome, D. (2016). The development of building assessment criteria framework for sustainable non-residential buildings in Saudi Arabia. Sustainable Cities and Society, 26, 289-305. doi.org/10.1016/j.scs.2016.07.007

Berechman, J. and Paaswell, R. E. (2005). Evaluation, prioritization and selection of transportation investment projects in New York City. Transportation, 32: 223-249. doi: 10.1007/s11116-004-7271-x.

Benayoun, R., Roy, B., \& Sussman, N. (1966). Manual de Reference du programme electre, Mote de Synthese et Formaton, No. 25, Direction Scientifique SEMA, Paris, France.

Bertone, E., Sahin, O., Stewart, R. A., Zou, P., Alam, M., \& Blair, E. (2016). State-of-the-art review revealing a roadmap for public building water and energy efficiency retrofit projects. International Journal of Sustainable Built Environment, 5(2), 526-548. doi.org/10.1016/j.ijsbe.2016.09.004

Brans, J.P. \& Vincke, P. (1985). A preference ranking organization method (The PROMETHEE method for multiple criteria decision making). Management Science, 31(6), 647-656.

Bibri, S. E. \& Krogstie, J. (2017). 'Smart sustainable cities of the future: an extensive interdisciplinary literature review', Sustainable Cities and Society, vol. 31, pp. 183-212.

Cabeza, L.F., Rincón, L., Vilariño, V., Pérez, G. and Castell, A. (2013). Life cycle assessment (LCA) and life cycle energy analysis (LCEA) of buildings and the building sector: a Review. Renewable and Sustainable Energy Reviews, 29: 394-416. doi: 10.1016/j.rser.2013.08.037.

Callaway, L. (2016). Smart cities: The future of sustainable living. Renewable Energy Focus, 17(3), 106108. https://doi.org/10.1016/j.ref.2016.05.005

Carli, R., Dotoli, M., Pellegrino, R. (2017). A hierarchical decision making strategy for the energy management of smart cities. IEEE Trans. Autom. Sci. Eng. 14 (2), 505-523. doi.org/10.1109/TASE.2016.2593101.

Chidiac, S.E., Catania, E.J.C., Morofsky, E. \& Foo, S., (2011). A screening methodology for implementing cost effective energy retrofit measures in Canadian office buildings. Energy Build. 43, 614-620.

Controller and Auditor-General Office (2013). Public sector financial sustainability. New Zealand Parliament, 40p.

del Caño, A, de la Cruz, M.P., Gómez, D. and Pérez, M. (2016). Fuzzy method for analysing uncertainty in the sustainable design of concrete structures. Journal of Civil Engineering and Management, 22 (7): 924935. doi: 10.3846 / 13923730.2014.928361. 
de la Fuente, A., Pons, O., Aguado, A. and Josa, A., (2016). Multicriteria-decision making in the sustainability assessment of sewerage pipe systems. J. Clean. Prod., 112 (5): 4762-4770. doi: 10.1016/j.jclepro.2015.07.002.

de la Fuente, A., Blanco, A., Armengou, J. and Aguado, A. (2017). Sustainability based-approach to determine the concrete type and reinforcement configuration of TBM tunnels linings. Case study: Extension line to Barcelona Airport T1. Tunnelling \& Underground Space Technology, 61: 179-188. doi. 10.1016/j.tust.2016.10.008

Dong, Y., Miraglia, S., Manzo, S., Georgiadis, S., Sørup, H. J. D., Boriani, E., ... Hauschild, M. Z. (2018). Environmental sustainable decision making- The need and obstacles for integration of LCA into decision analysis. Environmental Science and Policy, 87(May), 33-44. doi.org/10.1016/j.envsci.2018.05.018

Drew, J., \& Dollery, B. (2015). Inconsistent Depreciation Practice and Public Policymaking: Local Government Reform in New South Wales. Australian Accounting Review, 25(1), 28-37. doi.org/10.1111/auar.12072

European Committee for Standardization (2002). EN 1990: Eurocode - Basis of structural design. European Union, 119p.

European Parliament (2010). Directive 2010/31/EU of the European Parliament and of the council of 19 May 2010 on the energy performance of buildings. Official Journal of the European Union, 23 p.

Forsberg, A. \& Malmborg, F. (2004). Tools for environmental assessment of the built 9environment, Build. Environ. 39 (2): 223-228.

Gray, R., Dillard, J. and Spence, C., (2009). Social accounting research as if the world matters: an essay in Postalgia and a New Absurdism. Public Management Review, 11: 545-573. doi: 10.1080/14719030902798222.

Guarini, M.R., Chiovitti, A., Battisti, F. \& Morano, P. (2017). An integrated approach forthe assessment of urban transformation proposals in historic and consolidatedtissues, in: G. Borruso, et al. (Eds.), ICCSA, Vol. 10406 LNCS, pp.562-574

Gynther, L., Lappillone, B., \& Pollier, K. (2015). Energy efficiency trends and policies in the household and tertiary sectors. An analysis based on the ODYSSEE and MURE databases, (June), 97. Retrieved from http://www.odyssee-mure.eu/publications/br/energy-efficiency-trends-policies-buildings.pdf (last access 26 August 2018)

Huang, I.B., Keisler, J., and Linkov, I. (2011). Multi-criteria decision analysis in environmental sciences: Ten years of applications and trends. Science of the Total Environment, 409(19), 3578-3594. doi:/10.1016/j.scitotenv.2011.06.022.

Huang, I., Yan, L . and Wu, J. (2016). Assessing urban sustainability of Chinese megacities: 35 years after the economic reform and open-door policy. Landscape and Urban Planning, 145: 57-70. doi: 10.1016/j.landurbplan.2015.09.005.

Hwang, C.L., \& Yoon, K. (1981). Multiple attribute decisión making, in lecture notes in economics and mathematical systems 186. Berlin: Springer-Verlag.

Kabir, G., Sadiq, R., \& Tesfamariam, S. (2014). A review of multi-criteria decision-making methods for infrastructure management. Structure and Infrastructure Engineering, 10(9), 1176-1210. doi.org/10.1080/15732479.2013.795978 
Keeney, R.L. \& Raiffa, H., (1993). Decisions With Multiple Objectives: Preferences and Value Tradeoffs. Cambridge University Press, Cambridge.

Kylili, A., \& Fokaides, P. A. (2017). Policy trends for the sustainability assessment of construction materials: A review. Sustainable Cities and Society, 35, 280-288. https://doi.org/10.1016/j.scs.2017.08.013

Kunzmann, K.R. (2014). Smart cities. Crios 4 (1), 9-20.

Linkov, I., \& Moberg, E. (2011). Multi-criteria decision analysis: environmentalapplications and case studies. Boca Raton: CRC Press. ISBN 9781439853191

Liu, M., Balali, V., Wei H. and Peña Mora F. A. (2015). Scenario-based Multi-criteria Prioritization Framework for Urban Transportation Projects. American Journal of Civil Engineering and Architecture, 3 (6): 193-199. doi: 10.12691/ajcea-3-6-1.

Lopez-Carreiro, I., \& Monzon, A. (2018). Evaluating sustainability and innovation of mobility patterns in Spanish cities. Analysis by size and urban typology. Sustainable Cities and Society, 38(September 2017), 684-696. doi.org/10.1016/j.scs.2018.01.029

Marsal-Llacuna, M. -L., Colomer-Llinàs, J., \& Meléndez-Frigola, J. (2015). Lessons in urban monitoring taken from sustainable and livable cities to better address the Smart Cities initiative. Technological Forecasting and Social Change, 90(B), 611-622. doi.org/10.1016/j.techfore.2014.01.012.

Medineckiene, M., Zavadskas, E.K., Björk, F. and Turskis, Z. (2015). Multi-criteria decision-making system for sustainable building assessment/certification. Archives of civil and mechanical engineering, 15: 11-18. doi:10.1016/j.acme.2014.09.001.

Mendizabal, M., Heidrich, O., Feliu, E., García-Blanco, G., \& Mendizabal, A. (2018). Stimulating urban transition and transformation to achieve sustainable and resilient cities. Renewable and Sustainable Energy Reviews, 94(May), 410-418. doi.org/10.1016/j.rser.2018.06.003

Mori, K. and Christodoulou, A. (2012). Review of sustainability indices and indicators: towards a new City Sustainability Index (CSI). Environ. Impact Assess. Rev. 32, 94-106. doi:10.1016/j.eiar.2011.06.001.

Nesticò, A., Morano, P., \& Sica, F. (2018). A model to support the public administration decisions for the investments selection on historic buildings. Journal of Cultural Heritage, (2017). doi.org/10.1016/j.culher.2018.03.008

Nilashi, M., Zakaria, R., Ibrahim, O., Majid, M. Z. A., Mohamad Zin, R., Chugtai, M. W., ... Aminu Yakubu, D. (2015). A knowledge-based expert system for assessing the performance level of green buildings. Knowledge-Based Systems, 86(June), 194-209. doi.org/10.1016/j.knosys.2015.06.009

Opricovic, S. (1998), Multicriteria Optimization of Civil Engineering System. Faculty of Civil Engineering, Belgrade.

Ozawa-Meida, L., Wilson, C., Fleming, P., Stuart, G., \& Holland, C. (2017). Institutional, social and individual behavioural effects of energy feedback in public buildings across eleven European cities. Energy Policy, 110(July), 222-233. doi.org/10.1016/j.enpol.2017.08.026

Pan, W., Adrew, R. J., Dainty, M. A. S. C. E., \& Alistair, G. F. G. (2012). Establishingand weighting decision criteria for building system selection in housingconstruction. Journal of Construction Engineering and Management, 138,1239-1250.

Pardo-Bosch, F. and Aguado, A. (2015). Investment priorities for the management of hydraulic structures. Structure and Infrastructure Engineering, 11(10): 1338-1351. doi: 10.1080/15732479.2014.964267 
Pardo-Bosch, F. and Aguado, A. (2016). Sustainability as the key to prioritize investments in public infrastructures. Environ. Impact Assess. Rev., 60: 40-51. doi:10.1016/j.eiar.2016.03.007.

Pearce, A. R. (2017). Sustainable Urban Facilities Management. Encyclopedia of Sustainable Technologies (Vol. 2). Elsevier. doi.org/10.1016/B978-0-12-409548-9.10183-6

Persson, J. \& Grönkvist, S. (2015). Drivers for and barriers to low-energy buildings in Sweden. Journal of Cleaner Production, 109, 296-304

Phillis, Y. A., Kouikoglou, V. S., \& Verdugo, C. (2017). Urban sustainability assessment and ranking of cities. Computers, Environment and Urban Systems, 64, 254-265. doi.org/10.1016/j.compenvurbsys.2017.03.002

Ribeiro, J. M. P., Bocasanta, S. L., Ávila, B. O., Magtoto, M., Jonck, A. V., Gabriel, G. M., \& Guerra, J. B. S. O. de A. (2018). The adoption of strategies for sustainable cities: A comparative study between Seattle and Florianopolis legislation for energy and water efficiency in buildings. Journal of Cleaner Production, 197, 366-378. doi.org/10.1016/j.jclepro.2018.06.176

Rodríguez-Álvarez J. (2016 ). Urban Energy Index for Buildings (UEIB): A new method to evaluate the effect of urban form on buildings' energy demand. Landscape and Urban Planning, 148: 170-187. doi:10.1016/j.landurbplan.2016.01.001

Saaty, T.L. (1980). The analytic hierarchy process. New York: McGraw Hill.

San-Jose, J. and Garrucho, I. A. (2010). System approach to the environmental analysis industry of buildings. Build. Environ, 45: 673-683. doi:10.1016/j.buildenv.2009.08.012

Selih, J., Kne, A., Srdic, A. \& Zura, M. (2008). Multiple-criteria decision support system in highway infrastructure management, Transport 23 (4), 299-305.

Shealy, T., Johnson, E., Weber, E., Klotz, L., Applegate, S., Ismael, D., \& Bell, R. G. (2018). Providing descriptive norms during engineering design can encourage more sustainable infrastructure. Sustainable Cities and Society, 40, 182-188. doi.org/10.1016/j.scs.2018.04.017

Shelton, T., Zook, M. \& Wiig, A. (2015). The actually existing smart city. Camb. J. Reg. Econ. Soc. 8 (1), 1325.

Si, J., Marjanovic-Halburd, L., Nasiri, F., \& Bell, S. (2016). Assessment of building-integrated green technologies: A review and case study on applications of Multi-Criteria Decision Making (MCDM) method. Sustainable Cities and Society, 27, 106-115. doi.org/10.1016/j.scs.2016.06.013

Suganthi, L. (2018). Multi expert and multi criteria evaluation of sectoral investments for sustainable development: An integrated fuzzy AHP, VIKOR / DEA methodology. Sustainable Cities and Society, 43, 144-156. doi.org/10.1016/j.scs.2018.08.022

Tsamboulas, D. A. (2007). A tool for prioritizing multinational transport infrastructure investments. Transport Policy, 14: 11-26. doi:10.1016/j.tranpol.2006.06.001.

United Nations (2018). World Urbanization Prospects: the 2018 Revision. United Nations, New York: Department of Economic and Social Affairs

United Nations (2013). Sustainable development challenges. World Economic and Social Survey 2013. U. N. Publication, New York. ISBN: 978-92-1-109167-0 (181 pp.). 
United States Congress (1969). National Environmental Policy Act (NEPA). Public Law 91-190, Whashington (9 pp.).

Veldhuizen, L.J.L., Berentsen, P.B.M., Bokkers, E.A.M. and de Boer, I.J.M. (2015). Amethod to assess social sustainability of capture fisheries: an application to a Norwegian trawler. Environ. Impact Assess. Rev., 53: 31-39. doi:10.1016/j.eiar.2015.04.002.

World Commission on Environment and Development (1987). Our common future. Annex to document A/42/427 - development and international co-operation: environment. United Nations Documents (300 pp.).

Xu, P., Shen, Y., Chen, L., Mao, J., Chang, E. \& Ji, Y. (2015). Assessment of energy-saving technologies retrofitted to existing public buildings in China. Energy Efficiency 9, 67-94.

Yin, B. C. L., Laing, R., Leon, M., \& Mabon, L. (2018). An evaluation of sustainable construction perceptions and practices in Singapore. Sustainable Cities and Society, 39, 613-620. https://doi.org/10.1016/j.scs.2018.03.024 
Appendix: Supplementary Tables

Table A1.- Service life for each type of building.

\begin{tabular}{lc}
\hline Type of Structure & Service life \\
\hline Structures of a temporary nature. & 5 years \\
Mixed agricultural or industrial buildings. & 15 years \\
Concrete agricultural or industrial buildings. & 30 years \\
Housing or office buildings having a low or average economic repercussion. & 50 years \\
Buildings of a monumental nature or having a special importance. & 100 years \\
\hline
\end{tabular}

Table A2.- Variables and indicators qualifications

\begin{tabular}{|c|c|c|c|c|}
\hline & Medical Center A (P1) & Medical Center B (P2) & Police Station (P3) & School (P4) \\
\hline 11 & 102,000 & 64,000 & 50,000 & 74,000 \\
\hline $\mathrm{VI}_{1}$ & 0.51 & 0.77 & 0.84 & 0.71 \\
\hline 12 & 45.5 & -28.32 & -22.64 & -4.5 \\
\hline $\mathrm{VI}_{2}$ & 0 & 0.96 & 0.95 & 0,43 \\
\hline 13 & 100,000 & 65,000 & 37,500 & 55,000 \\
\hline $\mathrm{VI}_{3}$ & 0.68 & 0.84 & 0.95 & 0.88 \\
\hline 14 & 5 & 3 & 1 & 1 \\
\hline $\mathrm{VI}_{4}$ & 1 & 0.5 & 0 & 0 \\
\hline 15 & 1 & 1 & 3 & 5 \\
\hline $\mathrm{Vl}_{5}$ & 0 & 0 & 0.5 & 1 \\
\hline $\begin{array}{c}16 \\
\text { (RM/LM/NrM) }\end{array}$ & $\begin{array}{c}9 \\
(5 / 1 / 3)\end{array}$ & $\begin{array}{c}5 \\
(1 / 1 / 3)\end{array}$ & $\begin{array}{c}15 \\
(5 / 5 / 5)\end{array}$ & $\begin{array}{c}5 \\
(1 / 1 / 3)\end{array}$ \\
\hline $\mathrm{VI}_{6}$ & 0.76 & 0.14 & 1 & 0.14 \\
\hline $\begin{array}{c}17 \\
\text { (RA/RWU/TGW/EIS) }\end{array}$ & $\begin{array}{c}1 \\
\text { (No/Yes/No/No) }\end{array}$ & $\begin{array}{c}1 \\
\text { (No/Yes/No/No) }\end{array}$ & $\begin{array}{c}2 \\
\text { (No/Yes/Yes/No) }\end{array}$ & $\begin{array}{c}1 \\
\text { (No/Yes/No/No) }\end{array}$ \\
\hline $\mathrm{Vl}_{7}$ & 0.25 & 0.25 & 0.5 & 0.25 \\
\hline $\begin{array}{c}18 \\
\text { (EPC/EP) }\end{array}$ & $\begin{array}{c}9 \\
(6 / 3)\end{array}$ & $\begin{array}{c}9 \\
(6 / 3)\end{array}$ & $\begin{array}{c}10 \\
(7 / 3)\end{array}$ & $\begin{array}{c}9 \\
(6 / 3)\end{array}$ \\
\hline $\mathrm{VI}_{8}$ & 0.7 & 0.7 & 0.8 & 0.7 \\
\hline 19 & $2 / 3$ & 1 & 0 & $6 / 7$ \\
\hline $\mathrm{Vl}_{9}$ & 0.43 & 0.17 & 1 & 0.28 \\
\hline 110 & $50 \%$ & $10 \%$ & $100 \%$ & $15 \%$ \\
\hline $\mathrm{Vl}_{10}$ & 0.5 & 0.1 & 1 & 0.15 \\
\hline 111 & 5 & 5 & 3 & 5 \\
\hline $\mathrm{VI}_{11}$ & 1 & 1 & 0.5 & 1 \\
\hline $\begin{array}{c}112 \\
(\mathrm{CJ} / \mathrm{EJ} / \mathrm{CD} / \mathrm{SL})\end{array}$ & $\begin{array}{c}30.45 \\
(30 / 15 / 1.5 / 50)\end{array}$ & $\begin{array}{c}2.3 \\
(2 / 12 / 1.25 / 50)\end{array}$ & $\begin{array}{c}25.3 \\
(25 / 10 / 1.5 / 50)\end{array}$ & $\begin{array}{c}15.2 \\
(15 / 15 / 0.75 / / 50)\end{array}$ \\
\hline $\mathrm{VI}_{12}$ & 0.91 & 0 & 0.81 & 0,42 \\
\hline 113 & 5 & 3 & 3 & 5 \\
\hline $\mathrm{VI}_{13}$ & 1 & 0,5 & 0,5 & 1 \\
\hline Bs & 0.58 & 0.46 & 0.83 & 0.51 \\
\hline
\end{tabular}

